\title{
Pemasangan Sistem Telemetri Untuk Pemantauan Aktivitas Gunungapi (Studi Kasus Pemantauan Suhu G. Kelud, Jawa Timur)
}

\author{
Imam Suyanto*, Wahyudi and Eddy Hartantyo
}

Received: 11 Feb., 2020 | Accepted: 6 Maret., 2020 | Published: 17 Aug., 2020 | DOI: 10.22146/jfi.v24i2.53900

\begin{abstract}
Ringkasan
Seringkali pemantauan gunungapi yang dilakukan secara langsung sangat berbahaya, terutama pada saat ada kenaikan aktivitas. Untuk itu diperlukan upaya agar pemantauan gunungapi dapat dilakukan dari jarak yang aman. Untuk maksud tersebut telah dibuat rancang bangun sistem telemetri, yang untuk langkah pertama digunakan untuk memantau perubahan suhu kawah Gunung Kelud, Kabupaten Kediri, Propinsi Jawa Timur. Sistem telemetri yang telah terpasang diharapkan dapat digunakan dalam jangka waktu lama, minimal dalam 1 tahun mendatang akan terus dievaluasi. Pemantauan bisa dilakukan 24 jam sehingga jika terjadi keadaan kritis dapat segera diketahui.

Penelitian dimulai dengan merancang sistem telemetri yang praktis, berbiaya rendah, dan mudah dalam perawatannya. LoRaWAN (Long Range Wide Area Network) dipilih karena dapat mendukung tujuan tersebut. Parameter suhu dipilih untuk diamati karena tidak memerlukan pencacahan tinggi dan dapat mencerminkan adanya dinamika dari Gunung Kelud.
\end{abstract}

Kata Kunci : Sistem telemetri, suhu, Gunung Kelud.

Abstract

Direct, in situ volcanic monitoring/measurements are dangerous especially when volcanic activity is increasing. For this reason, efforts are needed so that volcanic monitoring can be carried out from a safe distance. This paper shows a telemetry system design which has been made to monitor changes in the temperature of the crater of Mount Kelud, East Java. The installed telemetry system is expected to be used for a long time, at least in the next 1 year will continue to be evaluated. Monitoring can be done 24 hours so that in the event of a critical situation can be immediately identified.

The research began by designing a telemetry system that is practical, low cost, and easy to maintain. LoRaWAN (Long Range Wide Area Network) was chosen because it can support this goal. The temperature parameter was chosen to be observed because it does not require high data sampling and reflects the dynamics of Kelud volcano.

Keywords: telemetry system; temperature; Kelud Volcano.

\section{PENDAHULUAN}

Aktivitas gunungapi ditunjukkan dengan adanya perubahan berbagai parameter fisika yang ada di sekitar gunungapi tersebut, seperti kegempaan, deformasi, suhu kawah, medan gravitasi, medan magnet, dsb $[1,2]$. Dengan pemantauan berbagai

\footnotetext{
${ }^{*}$ Correspondence: imamsuyanto@ugm.ac.id

Departemen Fisika, Fakultas Matematika dan Ilmu Pengetahuan ,

Universitas Gadjah Mada, Yogyakarta, Indonesia

Full list of author information is available at the end of the article

${ }^{\dagger}$ Equal contributor
}

parameter fisika tersebut, maka tingkat aktivitas gunungapi dapat ditentukan. Penentuan tingkat aktivitas gunungapi sangat penting dalam melakukan mitigasi bencana letusan gunungapi [3].

Mitigasi bencana gunungapi merupakan hal yang sangat penting dan harus dilakukan. Salah satu bentuk mitigasi bencana letusan gunungapi adalah dengan memantau dan memetakan parameter-parameter fisis yang terkait dengan aktivitas gunungapi. Distribusi dan perubahan suhu merupakan parameter fisis yang 
terkait langsung dengan dinamika magma di dalam kantong magma gunungapi [4]. Aktivitas gunungapi di bawah permukaan berpengaruh terhadap suhu permukaan gunungapi tersebut, sehingga pemantauan suhu (termal) baik di kawah maupun di permukaan gunungapi sangat penting dilakukan dalam rangka monitoring aktivitas gunungapi.

Monitoring dan evaluasi terhadap Gunungapi Kelud sudah cukup banyak dilakukan, diantaranya evaluasi terkini tentang urutan erusi pada tanggal 13 Februari 2014 oleh Maeno, dkk (2019) [5], evaluasi tentang precursor seismic yang berbeda antara letusan evusif tahun 2007 dan letusan tipe Plinian tahun 2014 oleh Nakamichi, dkk. (2019) [6], hingga pemetaan secara spasial untuk mendapatkan faktor kebencanaan disekitar gunungapi Kelud ketika erupsi [7]. Oleh sebab itu, langkah monitoring setelah terjadinya erupsi 2014 sangat diperlukan. Dalam paper ini akan disajikan salah satu tipe monitoring suhu kawah baru di gunungapi Kelud yang menggunakan jaringan radio, dan data ditampilkan secara real time lewat jaringan internet. Langkah ini sebagai tambahan informasi yang dapat dipergunakan oleh instansi yang berwenang dan kajian terbuka para peneliti karena data yang disajikan dapat diakses secara bebas.

\section{METODE PENELITIAN}

Gambaran desain secara umum dalam monitoring ini disajikan pada gambar 1 . Instrument set pertama yang digunakan adalah set sensor dan data collecting, komunikasi data melalui VHF radio dalam system Lora, diterima oleh Repeater dan gateway, kemudian melalui koneksi internet akan dipanggil dan dikirimkan ke server jaringan. Langkah akhir adalah visualisasi hasil pengukuran.

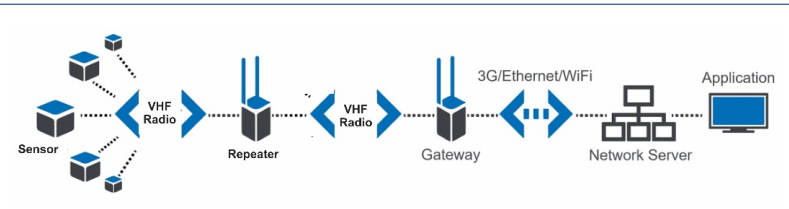

Gambar 1: Blok diagram sistem telemetri termal G. Kelud yang dibuat.

Suhu kawah diukur menggunakan sensor thermocouple dan LM35 yang dipasang di bibir kawah. Sensor thermocouple dan LM35 tersebut telah terintegrasi oleh mikrokontroler yang terhubung dengan Modul LoRa. Unit ini dilengkapi dengan sistem catu daya solar panel. Modul LoRa kemudian mengirim data bacaan suhu yang telah termodulasi ke Unit Repeater yang terletak pada bibir Kaldera Gunung Kelud. Repeater dipasang pada lokasi ini agar dapat terhubung dengan Pos Pengamatan Gunung Kelud yang terletak di Lereng. Repeater berfungsi untuk meneruskan data dari pemancar Modul LoRa yang berada di bibir kawah ke Modul LoRa Penerima yang berada di Pos Pengamatan. Visualisasi perlatan sensor, repeater dan gateway dapat dilihat pada gambar 2. Ketiga sub sistem tersebut terpisah dan dapat berkomunikasi satu dengan lainnya menggunakan low-power VHF radio.

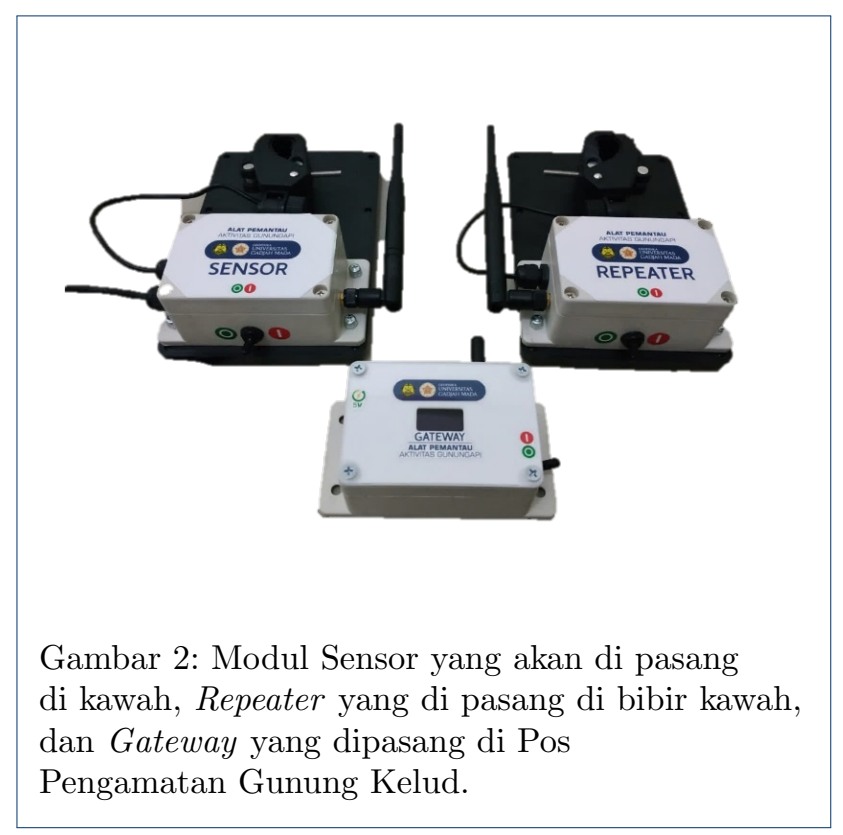

Sistem pengiriman data nirkabel jarak jauh atau biasa disebut telemetri pada penelitian ini memanfaatkan teknologi LoRa. LoRa (kependekan dari Long Range) adalah teknik modulasi spread spectrum yang berasal dari teknologi chirp spread spectrum (CSS). Teknologi ini merupakan platform transfer data nirkabel berdaya rendah jarak jauh yang telah dipakai untuk jaringan Internet of Things (IoT) di seluruh dunia. Teknologi LoRa memungkinkan aplikasi IoT pintar yang memecahkan beberapa tantangan terbesar yang dihadapi seperti: manajemen energi, pengurangan sumber daya alam, pengendalian polusi, efisiensi infrastruktur, pencegahan bencana, dan banyak lagi.

Modul LoRa yang berada di pos pengamatan dilengkapi dengan rangkaian demodulator yang berfungsi mengubah hasil modulasi data kembali ke nilai data bacaan suhu. Nilai bacaan suhu ini kemudian didigitasi dan dikirimkan ke Network Server melalui jaringan Seluler 3G menggunakan Modem Seluler. Server menyimpan data tersebut kedalam database dan mengolah serta menampilkan hasil bacaan suhu tersebut ke End User. 


\section{HASIL DAN PEMBAHASAN}

Pada ujicoba pemasangan subsistem (gambar 2) pada kawah gunungapi Kelud, maka sub sistem sensor harus diasangkan pada sebuah pengapung yang terbuat dari paralon. Pengapung didesain untuk dapat membawa sistem sensor, solar panel, dan catu daya, lihat gambar 3. Gambar 3a menunjukkan instrumen saat ujicoba di basecamp, dan gambar 3b menunjukkan foto saat terapung di kawah.
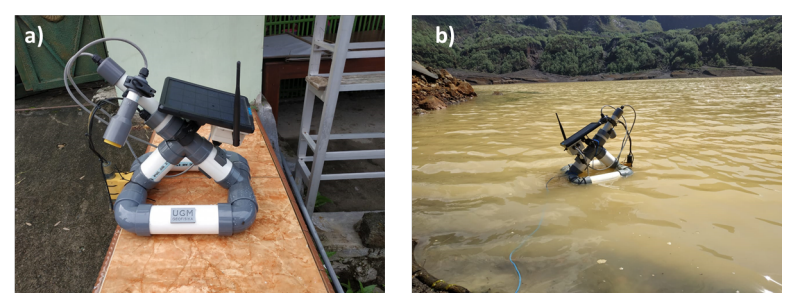

Gambar 3: Desain pengapung yang membawa sensor dan radio komunikasinya, batere dan solar panel saat uji coba di basecamp (a) dan di kawah (b).

Repeater yang digunakan sebagai penyampung informasi antara sensor dan gateway dipasangkan pada goa tembus yang berada pada lereng utara kawah gunungapi Kelud. Jarak antara keduanya kurang dari $4 \mathrm{~km}$ dan masih dapat berkomunikasi dengan baik, antara sensor yang berada di pengapung dan repeater yang berada di tebing mulut goa. Posisi repeater ini dipilih cukup tinggi, supaya dapat berkomunikasi dengan gateway yang dipasangkan pada basecamp vulkanologi di lereng gunungapi kelud.

Gateway yang digunakan dapat berkomunikasi dengan baik, sehingga data rekaman dapat dikirimkan melalui server jaringan dan dapat ditampilkan dengan baik, Data ditampilkan dengan media penampil grafik dan gambar di "thingspeak" yang dapat diakses di https://thingspeak.com/channels/849437. Tampilan data realtime dapat dilihat pada gambar 4 .

Suhu kawan dapat dilihat pada bagian atas dari halaman web yang ditunjukkan (gambar 4a) beserta peta googlemap. Data juga dapat diunduh dalam bentuk data Jason, XML dan CSV ascii yang sudah berurutan dalam data domain waktu.

\section{KESIMPULAN}

Perekaman dan monitoring suhu kawah di gunungapi Kelud dapat dilakukan dengan memanfaatkan sistem radio dan gateway LORA yang sangat sesuai untuk perekaman dan kontrol akuisisi data monitoring geofisika. Data suhu kawah juga dapat diakses secara realtime pada website dalam bentuk grafik dan data ascii dapat diakses juga untuk kepentingan kajian lebih lanjut.

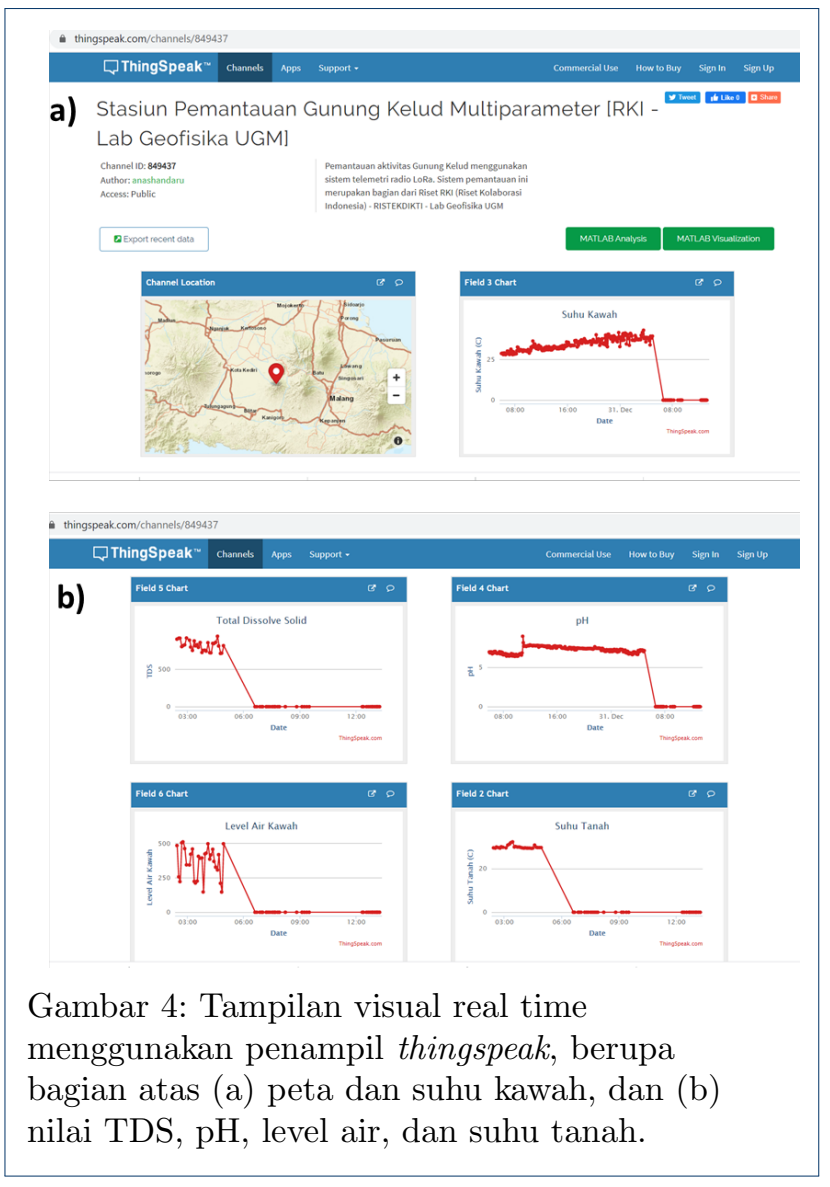

\section{PENULIS}

1 Imam Suyanto

Dari :

(1) ) Departemen Fisika, Fakultas Matematika dan Ilmu Pengetahuan, Universitas Gadjah Mada

2 Wahyudi

Dari :

(1) Departemen Fisika, Fakultas Matematika dan Ilmu Pengetahuan, Universitas Gadjah Mada

3 Eddy Hartantyo

Dari :

(1) Departemen Fisika, Fakultas Matematika dan Ilmu Pengetahuan, Universitas Gadjah Mada

Pustaka

1. Spampinato L, Calvari S, Oppenheimer C, Boschi E. Volcano surveillance using infrared cameras. Earth-Science Reviews. 2011;106(1-2):63-91.

2. Inguaggiato S, Diliberto IS, Federico C, Paonita A, Vita F. Review of the evolution of geochemical monitoring, networks and methodologies applied to the volcanoes of the Aeolian Arc (Italy). Earth-Science Reviews. 2018;176:241-276.

3. Alpala J, Alpala R, Battaglia M. Monitoring remote volcanoes: the 2010-2012 unrest at Sotará volcano (Colombia). Journal of Volcanology and Geothermal Research. 2017;344:224-231. 
4. Feseker T, Dählmann A, Foucher JP, Harmegnies F. In-situ sediment temperature measurements and geochemical porewater data suggest highly dynamic fluid flow at Isis mud volcano, eastern Mediterranean Sea. Marine Geology. 2009;261(1-4):128-137.

5. Maeno F, Nakada S, Yoshimoto M, Shimano T, Hokanishi N,

Zaennudin A, et al. A sequence of a plinian eruption preceded by dome destruction at Kelud volcano, Indonesia, on February 13, 2014, revealed from tephra fallout and pyroclastic density current deposits. Journal of Volcanology and Geothermal Research. 2019;382:24-41.
6. Nakamichi H, Iguchi M, Triastuty $\mathrm{H}$, Hendrasto M, Mulyana I. Differences of precursory seismic energy release for the 2007 effusive dome-forming and 2014 Plinian eruptions at Kelud volcano, Indonesia. Journal of Volcanology and Geothermal Research. 2019;382:68-80.

7. Hizbaron DR, Hadmoko DS, Mei ETW, Murti SH, Laksani MRT, Tiyansyah AF, et al. Towards measurable resilience: Mapping the vulnerability of at-risk community at Kelud Volcano, Indonesia. Applied geography. 2018;97:212-227. 